\title{
Can early infection explain the sibling effect in adult atopy?
}

\author{
P. Cullinan*, J.M. Harris*, A.J. Newman Taylor*, M. Jones*, P. Taylor*, J.R. Dave*, P. Mills*, \\ S.A. Moffat*, C.W. White*, J.K. Figg*, A.M. Moon*, M.C. Barnes*
}

Can early infection explain the sibling effect in adult atopy? P. Cullinan, J. M. Harris A.J. Newman Taylor, M. Jones, P. Taylor, J.R. Dave, P. Mills, S.A. Moffat, C.W. White, J.K. Figg, A.M. Moon, M.C. Barnes. (C) ERS Journals Ltd 2003.

ABSTRACT: Atopy is strongly and inversely related to family size, a pattern which is plausibly assumed to reflect a protective effect of early infection. The current study tested this hypothesis by case-referent analysis of an adult cohort in the UK.

The study established that atopy, defined by prick tests to common aeroallergens, was less common among those from larger families after adjustment for potentially confounding factors. In particular, a higher number of brothers appeared to offer protection. The current authors attempted to explain this distribution by examining contemporary family-doctor records of early childhood infections; and by a number of other indirect indices of early-life "hygiene".

The sibling effect was unexplained by evidence of infection with either hepatitis A or Helicobacter pylori, or by counts of infections or antibiotic prescriptions in early life. There was a significant and independent negative association between the number of gastrointestinal infections before the age of 5 yrs and the odds of atopy. Dog ownership and home moving in early life also displayed potentially protective associations.

Although the current study replicates the finding that atopy is inversely associated with family size this could not be explained by documentary or serological evidence of early infection. The findings support the suggestion that the "sibling effect" in atopy may not simply reflect protection by early infection.

Eur Respir J 2003; 22: 956-961.
*Depts of Occupational and Environmental Medicine and ${ }^{\#}$ Microbiology, Imperial College School of Medicine (NHLI), London, UK.

Correspondence: P. Cullinan, Dept of Occupational and Environmental Medicine, Imperial College School of Medicine (NHLI), Manresa Road, London, SW3 6LR, UK.

Fax: 442073518336

E-mail: p.cullinan@ic.ac.uk

Keywords: Atopy

early infection

family size

hygiene

Received: May 102003

Accepted after revision: July 222003

The study was supported by the Colt Foundation.
In a UK birth cohort, atopy and hay fever were more common among children from small families [1]. The same patterns have been replicated elsewhere, for example among German [2] and Italian [3] children. These epidemiological observations are commonly ascribed to lower rates of infection among first-born children or those with few siblings; it is argued that early encounters with infection encourage the preferential development of T-helper cell type 1 lymphocytes at the expense of T-helper cell type 2-subtypes associated with allergic responses to foreign proteins. Direct confirmation of this explanation is lacking although protective roles for measles in West Africa [4], mycobacteria in Japan [5] and gastrointestinally-acquired infections, particularly hepatitis A, in southern Italy [6], have been reported for atopy.

The present study sought a critical test for the hygiene theory among a population of UK adults. The current authors hypothesised that rates of atopy in this population would be inversely related to family size (an indirect marker of early infection), and also that direct markers of infection would be more common in larger families. The null hypothesis that the pattern of atopic risk in relation to family size would not be explained by direct evidence of early infection was subsequently tested.

\section{Materials and methods}

\section{Methods}

Over 18 months, from November 1993, all females presenting for antenatal care at three general practices in Ashford, Kent, were invited to enrol in a prospective study of childhood asthma. Six-hundred and twenty-five (93\% of those eligible) agreed and subsequently gave birth to at least one live infant, in nine cases on two occasions. The 625 "first-time" mothers and their partners form the base population for the analysis described in this report.

At recruitment all but three of the mothers and 542 (87\%) of the fathers underwent skin-prick tests with Allergopharma (Hamburg, Germany) allergens. Mothers and fathers are described as atopic if they had one or more positive (mean weal diameter $\geqslant 3 \mathrm{~mm}$ ) skin tests to extracts of Dermataphagoides pteronyssinus, cat fur or grass pollen.

By 1998/99, 15 mothers had asked to leave the study and one had died. At this point the remaining parents were re-interviewed. 1) A questionnaire was administered in person to $583(97 \%)$ mothers and $480(90 \%)$ of the 534 available partners. It elicited information on medical diagnoses of asthma, hayfever or eczema, sibling numbers and ages, pet ownership before the age of five, and some further domestic details. Participants were described as having a parental history of allergy if either parent had a diagnosis of asthma, hayfever or eczema. 2) Venous blood was collected from 898 $(84 \%)$ of the parents ( $87 \%$ of mothers and $81 \%$ of fathers) and assayed for specific immunoglobulin (Ig)G antibodies to Helicobacter pylori (Sigma Diagnostics, Poole, UK), hepatitis A (Biokit Ltd, Longfield, UK) and Toxocara canis (TCS; Biosciences Ltd, Botolph Claydon, UK). In each case the cut-off points suggested by the manufacturers were used. 3) For each adult, contemporary general practice notes were scrutinised for details of infective illnesses and antibiotic prescriptions up to the age of 5 yrs. Medical records were 
obtained for 1,028 (97\%) participants; in 746 (73\%) there was information covering early childhood. Early records were less often available for males $(71 \%)$ than females $(74 \%)$ and for those aged $\geqslant 35$ yrs $(58 \%)$ than those who were younger $(80 \%)$. Using pre-determined criteria, two researchers, unaware of the atopic status of the participants, transcribed records of consultations for each infective illness in the first 5 yrs of life; there were no important differences in their transcriptions. Infections were categorised by type, and consultations for the same infection type $<28$ days apart were considered a single episode. Antibiotic prescriptions, by antibiotic class and indication, were counted and categorised in the same way. Information on vaccination was unreliably recorded and this issue is not discussed further.

The mean age of those who took part in the interviews was 28 yrs (SD 5 yrs), the same as in the base population. There were no differences in blood sampling or the availability of relevant records between those who were and were not atopic.

The ethical committee of the National Heart and Lung Institute, London, approved the study.

\section{Statistical methods}

In the main, the analyses below concern potential determinants of atopic status. Most results are expressed as odds ratios (OR) with 95\% confidence intervals (CI) derived from logistic regression analyses. Simple, descriptive analyses have also been conducted using unpaired t-tests and Chi-squared statistics as appropriate.

\section{Results}

\section{Atopy}

Three hundred and ninety-two (37\%) participants were atopic, a frequency significantly higher $(\mathrm{p}=0.02)$ among males and among those with a parental history of allergy $(\mathrm{p}=0.01$; table 1). Atopy was also more common among those aged $\geqslant 35$ yrs and those in higher socioeconomic groups although these associations were not statistically significant. There was a clear and inverse relationship between rates of atopy and the number of siblings during early life with an OR of 0.85 (95\% CI 0.77-0.94) per extra sibling. This relationship was determined by the number of brothers (OR $0.76(0.60-0.87)$ ) rather than sisters (OR $0.96(0.84-1.08)$ ); statistically, a model including brothers and sisters separately was a significantly better fit than that including siblings alone $(\mathrm{p}=0.02$; likelihood-ratio test). The inverse association with siblings was no different when older or younger siblings were examined (OR per older sibling 0.91, per younger sibling 0.86; likelihood ratio test $\mathrm{p}=0.50$ ) but was strongest when younger brothers were assessed independently (OR 0.67 (0.55-0.81)). None of these associations was changed by statistical adjustment for age, sex, socioeconomic group and parental history of allergic disease.

\section{Infections}

Positive serology for hepatitis A was uncommon (9\%) and rarer than a positive test for $H$. pylori $(17 \%)$. Each was more common with increasing age (adjusted $\mathrm{p}<0.001$ and $\mathrm{p}=0.05$ respectively); and among males and in those from lower socioeconomic groups although these last differences were small and not statistically significant (table 2). A positive test for $H$. pylori was significantly (adjusted $\mathrm{p}<0.001$ ) more common among those with many brothers in early life; although the same was true for also positive hepatitis A serology, the pattern was not statistically significant $(\mathrm{p}=0.23)$.

At least one infection before the age of 5 yrs was recorded in almost all $(93 \%)$ the examined general practice notes. Three or more infections were more often recorded for younger participants but less commonly among those from larger families; these patterns were statistically significant (table 2).

Table 1.-Sociodemographic associations with atopy

\begin{tabular}{|c|c|c|c|c|c|c|}
\hline & Subjects $n$ & n (\%) atopic* & OR $(95 \% \mathrm{CI})$ & p-value & Adjusted OR ${ }^{\#}(95 \%$ CI $)$ & p-value \\
\hline \multicolumn{7}{|l|}{ Age } \\
\hline$\leqslant 30 \mathrm{yrs}$ & 366 & $123(34)$ & $1.02(1.00-1.05)^{\S}$ & 0.10 & $1.01(0.99-1.04)^{\S}$ & 0.31 \\
\hline $31-34$ yrs & 335 & $124(37)$ & & & & \\
\hline$\geqslant 35$ yrs & 349 & $145(42)$ & & & & \\
\hline \multicolumn{7}{|l|}{ Sex } \\
\hline $\mathrm{F}$ & 582 & 199 (34) & 1.00 & 0.02 & 1.00 & 0.02 \\
\hline M & 468 & 193 (41) & $1.35(1.05-1.74)$ & & $1.40(1.05-1.86)$ & \\
\hline \multicolumn{7}{|c|}{ Parental allergy } \\
\hline No & 660 & 224 (34) & 1.00 & 0.01 & 1.00 & 0.002 \\
\hline Yes & 335 & $144(43)$ & $1.47(1.12-1.92)$ & & $1.59(1.19-2.12)$ & \\
\hline \multicolumn{7}{|l|}{ Social class } \\
\hline $\mathrm{I} / \mathrm{II}$ & 168 & $67(40)$ & 1.00 & 0.50 & 1.00 & 0.72 \\
\hline III & 564 & $216(38)$ & $0.94(0.66-1.33)$ & & $0.96(0.67-1.38)$ & \\
\hline IV/V & 234 & $81(35)$ & $0.80(0.53-1.20)$ & & $0.85(0.56-1.31)$ & \\
\hline \multicolumn{7}{|c|}{ No. of brothers } \\
\hline 0 & 334 & $147(44)$ & $0.76(0.60-0.87)^{+}$ & $<0.001$ & $0.77(0.66-0.89)^{+}$ & $<0.001$ \\
\hline 1 & 453 & $172(38)$ & & & & \\
\hline 2 & 179 & $51(28)$ & & & & \\
\hline $3+$ & 84 & $22(26)$ & & & & \\
\hline \multicolumn{7}{|l|}{ No. of sisters } \\
\hline 0 & 340 & $125(37)$ & $0.96(0.84-1.08)^{f}$ & 0.48 & $0.94(0.81-1.08)^{f}$ & 0.39 \\
\hline 1 & 437 & $173(40)$ & & & & \\
\hline 2 & 199 & $69(35)$ & & & & \\
\hline $3+$ & 74 & $25(34)$ & & & & \\
\hline
\end{tabular}

F: female; M: male; OR: odds ratio; CI: confidence interval. *: one or more positive skin tests to extracts of Dermataphagoides pteronyssinus, cat fur or grass pollen; ${ }^{\#}$ : adjusted for the other factors in the table; ${ }^{\S}$ : per year; ${ }^{+}$: per brother; ${ }^{f}$ : per sister; ${ }^{\uparrow}$ : defined by occupation: I/II professional/ intermediate, III skilled nonmanual/manual, IV/V unskilled. 
Table 2.-Sociodemographic associations with markers of early infection

\begin{tabular}{|c|c|c|c|c|c|c|c|}
\hline & $\begin{array}{l}\text { Subjects } \\
\text { n }\end{array}$ & $\begin{array}{c}\text { n (\%) } \\
\text { HAV +ve }\end{array}$ & $\begin{array}{l}\text { Adjusted OR* } \\
\qquad(95 \% \mathrm{CI})\end{array}$ & $\begin{array}{c}\mathrm{n}(\%) \\
\text { H. pylori }+\mathrm{ve}\end{array}$ & $\begin{array}{l}\text { Adjusted OR* } \\
\qquad(95 \% \mathrm{CI})\end{array}$ & $\begin{array}{c}\geqslant 3 \text { recorded } \\
\text { infections } \mathrm{n}(\%)\end{array}$ & $\begin{array}{l}\text { Adjusted OR* } \\
\quad(95 \% \mathrm{CI})\end{array}$ \\
\hline \multicolumn{8}{|l|}{ Age } \\
\hline$\leqslant 30$ & 305 & $16(5)$ & \multirow[t]{3}{*}{$1.13(1.08-1.19)^{\#}$} & $46(15)$ & \multirow[t]{3}{*}{$1.04(1.00-1.08)^{\#}$} & $236(80)$ & \multirow[t]{3}{*}{$0.91(0.88-0.95)^{\#}$} \\
\hline $31-34$ & 291 & $26(9)$ & & $49(17)$ & & $162(65)$ & \\
\hline$\geqslant 35$ & 302 & 37 (12) & & $56(19)$ & & $116(58)$ & \\
\hline \multicolumn{8}{|l|}{ Sex } \\
\hline $\mathrm{F}$ & 507 & $40(8)$ & 1.00 & $78(15)$ & 1.00 & $301(72)$ & \multirow[t]{2}{*}{$0.96(0.68-1.35)$} \\
\hline M & 391 & $39(10)$ & $0.79(0.47-1.33)$ & 73 (19) & $1.11(0.74-1.65)$ & $213(66)$ & \\
\hline \multicolumn{8}{|c|}{ Social class } \\
\hline I/II & 134 & $15(11)$ & 1.00 & $20(15)$ & 1.00 & $75(68)$ & 1.00 \\
\hline III & 495 & $37(8)$ & $0.78(0.40-1.50)$ & $73(15)$ & $1.09(0.63-1.88)$ & $289(69)$ & $0.96(0.61-1.53)$ \\
\hline IV/V & 197 & $21(11)$ & $1.07(0.51-2.22)$ & $36(18)$ & $1.24(0.68-2.29)$ & $112(67)$ & $0.91(0.53-1.55)$ \\
\hline \multicolumn{8}{|c|}{ No. of brothers } \\
\hline 0 & 283 & $28(10)$ & \multirow[t]{4}{*}{$1.15(0.92-1.43)^{\uparrow}$} & $35(12)$ & \multirow[t]{4}{*}{$1.34(1.13-1.58)^{\top}$} & $180(75)$ & \multirow[t]{4}{*}{$0.81(0.68-0.96)^{\top}$} \\
\hline 1 & 389 & $25(6)$ & & $61(16)$ & & $225(68)$ & \\
\hline 2 & 153 & $13(9)$ & & $34(22)$ & & $75(62)$ & \\
\hline $3+$ & 73 & $13(18)$ & & $21(29)$ & & $34(64)$ & \\
\hline
\end{tabular}

F: female; M: male; OR: odds ratio; CI: confidence interval; +ive: positive; HAV: hepatitis A virus. *: adjusted for all other factors in the table; ${ }^{\#}$ : per year; ": per brother.

No important variations were found when different types of infection were examined separately. Upper respiratory infections were most common (at least one in the first 5 yrs of life was recorded in $65 \%$ of all records), followed by lower respiratory $(56 \%)$, skin $(45 \%)$, and ear $(33 \%)$ infections. In $27 \%$ of records at least one gastrointestinal infection was recorded; and in 16\% there was a record of measles infection. For most categories of infection the median age of firstrecorded infection fell with increasing numbers of brothers: for example the median ages for first recorded gastro-intestinal infection were $1.91,1.77,1.21$ and 1.22 yrs respectively for adults with no, one, two and three or more brothers.

\section{Antibiotic prescriptions}

Seventy-six per cent $(n=564)$ of records contained one or more prescriptions for an antibiotic before the age of $5 \mathrm{yrs}$. The records for those aged $<31$ yrs $(84 \%)$ were more likely to contain an antibiotic prescription than those for participants aged $31-34(72 \%)$ yrs or older $(69 \%)$, a trend which was statistically significant $(\mathrm{p}<0.001)$. There were no important differences between males and females, between those from different socioeconomic groups or between those from variously sized families.

\section{Other factors}

Pet dogs were kept, during the first 5 yrs of life, by $42 \%$ of the population. This figure did not differ importantly between males and females, those of different ages or by socioeconomic group. There was, however, a consistent, positive relationship $(\mathrm{p}<0.001)$ with family size: those with no or a single sibling were much less likely to have kept a dog $(36 \%)$ than those with two $(42 \%)$, three $(48 \%)$ or more $(54 \%)$ siblings. The pattern was similar when brothers (and sisters) were examined separately. Those who had owned a dog were a little less likely $(66 \%)$ to have a record of three or more infections in their medical records than those without dogs $(71 \%, \mathrm{p}=0.03)$; there were no important differences between categories of infection.

Just under half $(462,44 \%)$ of participants had lived in the same home for their first 5 yrs; 92 (9\%) had moved home three or more times. The frequency of house moves was not related to family size $(\mathrm{p}=0.67)$.

\section{Atopy and infection}

Atopy was unrelated to a positive test for either hepatitis A or H. pylori (table 3 ). This lack of association was maintained across all age groups and was not modified by family size.

When all recorded infective episodes were considered, there was also no relationship with atopic status (table 3). Lower respiratory infections, however, were positively associated with atopy (OR 1.08 (1.01-1.14) per recorded episode) whereas gastrointestinal (and other) infections demonstrated a statistically significant inverse relationship (OR 0.73 (0.58-0.92) per recorded gastrointestinal episode). These relationships were maintained after adjustment for age, sex, socioeconomic status, parental allergic disease and number of brothers. Importantly the inverse association between numbers of brothers and atopy was unaffected by adjustment for any of the measures of early infection (table 3 ).

The adjusted odds ratios for recorded infective episodes at each age are plotted in the figure 1 . Those for respiratory infections increased each year to age $5 \mathrm{yrs}$; the opposite pattern was found for gastrointestinal infections. Atopy was less common among those with a recorded measles infection $(30 \%$ versus $38 \%)$ but the difference was not significant $(\mathrm{p}=0.11)$. When this was examined by age of infection, atopy was significantly $(\mathrm{p}=0.004)$ less common in the 28 adults who had a record of measles by age 3 yrs (11\% versus $38 \%$ ).

The prescription of antibiotics before 5 yrs was unrelated to subsequent atopy (OR 1.01 (0.97-1.05) per prescription). This lack of an association was found for all classes of and indications for antibiotics (data not shown). Risk estimates for antibiotic prescriptions (all types) tended to rise with age of prescription but the increases were small and none was statistically significant: OR $0.85,1.01,1.07,1.09$ and 1.09 per prescription at ages $<1-5$ yrs respectively (all $\mathrm{p}>0.05$ ).

\section{Atopy and other factors}

Ownership of a dog before the age of 5 yrs was strongly and inversely related to atopy (OR $0.72(0.56-0.93)$ ), an association which did not change after adjustment for age, 
Table 3.-Relationships between atopy and markers of early infection

\begin{tabular}{|c|c|c|c|c|c|c|c|c|}
\hline & \multicolumn{2}{|c|}{$\begin{array}{l}0 \text { infections (or } \\
\text { negative for } \\
\text { serology section) }\end{array}$} & \multicolumn{2}{|c|}{$\begin{array}{l}\geqslant 1 \text { infection (or } \\
\text { positive for } \\
\text { serology section) }\end{array}$} & \multirow{2}{*}{$\begin{array}{l}\text { Adjusted OR* } \\
(95 \% \mathrm{CI}) \\
\text { (per episode } \\
\text { for infections) }\end{array}$} & \multirow[t]{2}{*}{ p-value } & \multirow{2}{*}{$\begin{array}{l}\text { Adjusted OR } \\
(95 \% \mathrm{CI}) \text { for } \\
\text { association between } \\
\text { atopy and number } \\
\text { of brothers }\end{array}$} & \multirow[t]{2}{*}{$\mathrm{p}$-value } \\
\hline & $\mathrm{n}$ & n $(\%)$ atopic & $\mathrm{n}$ & n $(\%)$ atopic & & & & \\
\hline \multicolumn{9}{|l|}{ Serology } \\
\hline Hepatitis A serology & 818 & $303(37)$ & 78 & $28(36)$ & $0.96(0.56-1.64)$ & 0.88 & $0.81(0.69-0.94)$ & 0.01 \\
\hline Helicobacter serology & 745 & $278(37)$ & 151 & $53(35)$ & $0.87(0.57-1.33)$ & 0.52 & $0.81(0.70-0.95)$ & 0.01 \\
\hline \multicolumn{9}{|l|}{ Infections } \\
\hline All infections & 51 & $20(39)$ & 687 & $249(36)$ & $1.01(0.98-1.04)$ & 0.41 & $0.74(0.61-0.90)$ & 0.001 \\
\hline All respiratory infections & 167 & $61(37)$ & 571 & $208(36)$ & $1.03(0.99-1.07)$ & 0.13 & $0.74(0.62-0.90)$ & 0.001 \\
\hline All nonrespiratory infections & 138 & $52(38)$ & 600 & $217(36)$ & $0.99(0.94-1.05)$ & 0.72 & $0.73(0.61-0.89)$ & 0.001 \\
\hline Lower respiratory infections & 325 & $117(36)$ & 413 & $152(37)$ & $1.08(1.01-1.16)$ & 0.02 & $0.74(0.61-0.89)$ & 0.001 \\
\hline Upper respiratory infections & 263 & $92(35)$ & 475 & $177(37)$ & $1.00(0.94-1.07)$ & 0.93 & $0.74(0.61-0.89)$ & 0.001 \\
\hline Ear infections & 497 & $182(37)$ & 241 & $87(36)$ & $1.00(0.86-1.17)$ & 1.00 & $0.74(0.61-0.89)$ & 0.001 \\
\hline Skin infections & 404 & $148(37)$ & 334 & $121(36)$ & $1.05(0.94-1.17)$ & 0.37 & $0.74(0.62-0.90)$ & 0.002 \\
\hline Eye infections & 541 & $192(36)$ & 197 & 77 (39) & $1.21(0.96-1.51)$ & 0.10 & $0.74(0.62-0.90)$ & 0.001 \\
\hline Urinary tract infections & 669 & 247 (37) & 69 & $22(32)$ & $0.95(0.68-1.33)$ & 0.76 & $0.74(0.61-0.89)$ & 0.001 \\
\hline Gastrointestinal infections & 535 & $210(39)$ & 203 & $59(29)$ & $0.75(0.59-0.97)$ & 0.02 & $0.72(0.60-0.87)$ & 0.001 \\
\hline Other infections & 480 & $184(38)$ & 258 & $85(33)$ & $0.83(0.68-1.01)$ & 0.05 & $0.73(0.61-0.89)$ & 0.001 \\
\hline
\end{tabular}

OR: odds ratio; CI: confidence interval. *: adjusted for age, sex, social class, parental allergic disease and number of brothers; ${ }^{*}$ : adjusted for age, sex, social class, parental allergic disease and relevant infection count.

sex, socioeconomic status, parental allergic disease and number of brothers (table 4). Ownership of a cat (admitted to by $30 \%$ of the population) did not show any significant relationship with atopic status. Only two subjects $(0.2 \%$, both dog owners) had clear serological evidence of prior infection with $T$. canis.

Atopy was more common among those who did not move house before the age of $5 \mathrm{yrs}$ than those who moved once, twice or three times. This relationship was statistically significant $(p=0.02)$ and remained so after adjustment for the factors above including ownership of a dog.

After statistical adjustment for all potentially confounding factors (documentary or serological evidence of early infection, dog ownership or house moving) there was little change to the point estimate odds ratio for the association between atopy and number of brothers (OR $0.78(0.67-0.90))$. The same was true when all siblings were considered.

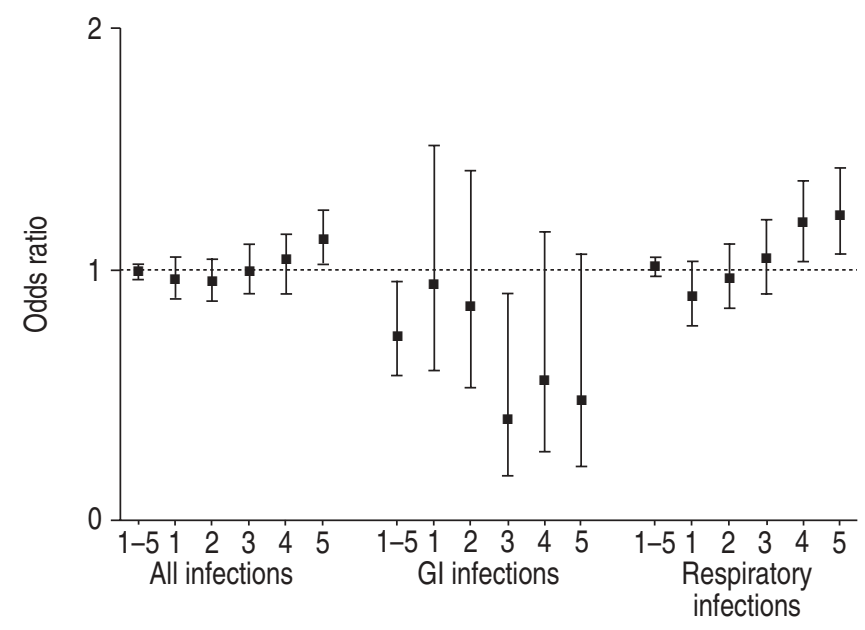

Age (yrs) at first infection and type of infection

Fig. 1.-Atopy odds ratios (adjusted for age, sex, social class, parental allergy and number of siblings) associated with infectious episodes before the age of 5 yrs and for $1-5$ yrs separately.

\section{Discussion}

This analysis confirms a clear inverse association between adult atopy and family size in early childhood, a pattern largely driven by the number of brothers. However, this could not be accounted for by several different indices of childhood infection. Conversely, apparently protective effects associated with early gastrointestinal infections with dog ownership and with moving home in the first 5 yrs of life were found. Although the current study's population is relatively small, it has the distinction of being highly representative of adults from South East England; both the participation and followup rates were high, and higher than those in other, similar studies. In addition the current authors used not only an objective outcome but were careful also to ensure blinded assessments of serological results and contemporary general practice records. The relationships found were unchanged by adjustment for several potential confounders suggesting that other important factors had not been neglected.

General practice records are inevitably an incomplete and potentially biased source of information about early infection. Many extraneous factors, including birth order, but also socioeconomic status, sex and era determine whether a parent will take her child to the doctor. In the present study's population, the existence of early, contemporary records was in part determined by age and was less common for males. The records examined were more likely to contain a mention of three or more infections before the age of $5 \mathrm{yrs}$ among those adults who were brought up in small families. However a systematic difference in seeking medical advice between parents with small and larger numbers of children [7] may have hidden a truly higher rate of infection among those from larger families. This is suggested by the higher rates of Helicobacter and hepatitis A infection in those with several siblings. As it happens, among contemporary UK families there is remarkably little evidence of a true relationship between infection and family size or birth order, although in Sweden [8] hospitalisation for respiratory infection and in the Netherlands [9] meningococcal carriage are both higher in large families. Even if not associated with a reduced risk of early infection, growing up in a small family may however increase the median age of first, relevant infection(s) [10], a pattern suggested by the records in this study. 
Table 4.- Other associations with atopy

\begin{tabular}{lccc}
\hline & Subjects n & n (\%) atopic & Adjusted OR* (95\% CI) \\
\hline Dog ownership age $<5$ yrs & & & 1.00 \\
$\quad$ No & 606 & $245(40)$ & $0.72(0.68-0.91)$ \\
$\quad$ Yes & 441 & $145(33)$ & 1.00 \\
Cat ownership age $<5$ yrs & 733 & $276(38)$ & $0.02(0.70-1.27)$ \\
$\quad$ No & 315 & $115(37)$ & $0.88(0.77-1.00)$ per move \\
$\quad$ Yes & 460 & $197(43)$ & \\
No. of house moves age $<5$ yrs & 372 & $118(32)$ & \\
0 & 119 & $48(40)$ & \\
1 & 88 & $26(30)$ & \\
2 & & & \\
3 & &
\end{tabular}

OR: odds ratio; CI: confidence interval. *: adjusted for age, sex, social class, parental allergic disease and number of brothers.

Positive serology for hepatitis A, a postulated marker for an unhygienic early childhood, was inversely associated with atopy among southern Italian military recruits [11]. The current study could not replicate this finding in a population where atopy was more common (37\% versus $28 \%$ in Italy) and evidence of hepatitis infection less frequent ( $9 \%$ versus $27 \%$ ). Similarly, in a small case-referent analysis from Aberdeen [12], where positive hepatitis A serology was much commoner (61\%), atopy was more often associated with a positive test although the difference was not statistically significant. The current study's rates of positivity to $H$. pylori were lower than those in Italy and Aberdeen (each 50\%) although the differences were less marked; in Italy this was also related, inversely, to atopic status a finding which again could not be replicated in the present study. These variations probably reflect different epidemiologies of early hepatitis A and Helicobacter infection in the UK and Italy.

Early lower-respiratory infections were more commonly recorded for atopic adults, a pattern which increased with the age of infection and which the current authors suggest reflects the emergence of accompanying asthma over the first $5 \mathrm{yrs}$ of life. Indeed the difficulty in separating cause from effect probably renders the epidemiological study of respiratory infections and allergic disease impossible, even when specific markers of infection are available. Conversely, recorded gastrointestinal infections were less common among atopic adults, a pattern which also strengthened with age of infection, which was seen despite the probable behavioural bias above and which remained after adjustment for possible confounding factors. A protective effect of such infections in early life is broadly consistent with the findings of a large survey in the USA [13]; and there is evidence that the gut colonisation in early life may affect the subsequent differentiation of T-cell populations [14]. Conversely, among a very large cohort of contemporary British children [15] no protective effect of early gastrointestinal infections on clinical diagnoses of asthma, hayfever or eczema was found; $\operatorname{IgE}$ antibody production was not examined, however, and the average period of follow-up was short (3 yrs). The information collected was insufficiently detailed to allow analysis of particular gastrointestinal infections although, at this age, most were probably viral. The current study's finding of an apparently protective effect of measles infection at age $3 \mathrm{yrs}$ should be interpreted with care since it is based on small numbers; and the infrequency with which this disease was recorded suggests a degree of underascertainment. It does however accord with findings of a study of asthma in Aberdeen [16].

In several respects the current findings are at variance with those of an earlier UK study of allergy and infections recorded in general practice records up to the age of $12 \mathrm{yrs}$
[17]. There, no relationship between sibship and recorded atopic disease (asthma, eczema or hayfever as described in the medical records) was found. Gastrointestinal infections were not reported as a separate category; but treatments with antibiotics for respiratory (particularly lower respiratory), urinary and skin infections in the first year of life were associated with markedly increased risk estimates for subsequent atopic disease. A survey of children aged 5-10 yrs attending Rudolph Steiner schools in New Zealand reported remarkably strong associations between antibiotic use and a history of asthma; particularly when symptoms of the latter started after the age of one and the drugs had first been prescribed during infancy [18]. Similar findings have been reported among German schoolchildren [19]. In none of these studies can recall or protopathic biases be excluded. Conversely, the present authors, using an objective definition of atopy derived separately from general practice records, were unable to confirm any significant increase in risk with any class of (or indication for) documented antibiotic use in the first 5 yrs. This is an important negative finding; and probably corroborates the recent findings for British children concerning early antibiotic use and clinical allergies [15].

In some other aspects the current findings are similar to those of a comparable, albeit larger, survey of adult atopy carried across Europe [20] although this did not include any direct markers of early infection. In that study individuals from large families, particularly those with many brothers, and, independently those who kept dogs, were less likely to be atopic. Indeed, the evidence indicating a protective effect of dog ownership is increasingly consistent [21] although not entirely so [22]. In the current study's population, the effect was strong and could not be accounted for by statistical adjustment for confounding factors, in particular family size. The specificity of the effect, both here and in the panEuropean study, is suggested by the absence of any such relationship with pet cats. A bias, whereby allergic families tend not to keep pets, is an improbable explanation for these findings. The relationship was not affected by adjustment for parental allergy, and an earlier report of this cohort showed that the keeping of a pet cat is unrelated to general or specific allergies within the family [23]. Bacterial, viral and parasitic infections may each be transmitted from dogs to humans [24] although with uncertain frequency, and the current authors suggest that the present findings support a protective role for early (unidentified) infection(s) in the development of atopy; alternatively levels of endotoxin, itself postulated to be protective, may be higher in homes where pets are kept [25]. The finding of reduced rates of atopy among those who had moved home in early life was unexpected; indeed an earlier study of childhood asthma suggested the opposite effect [26]. It is possible that moving home is associated with an 
increased rate of childhood infection (viral mixing) although the current authors are not aware of any direct evidence for this.

The current study was planned as a critical test of the plausible explanation for the inverse association between family size and atopic status: that higher rates of early infection among larger families are protective. The present study could not account for the relationship with sibship by several markers of early infection including evidence of infection with hepatitis A and Helicobacter pylori as observed in other populations. Within the Ashford birth cohort the current authors have recently reported [27] that mothers of small families are more likely to be atopic, a pattern that could not be accounted for by maternal age. This observation is as yet unexplained but together with the results reported here and elsewhere [28] suggests that the well-established inverse association between atopy and family size may be a manifestation of maternal or intra-uterine events rather than solely a reflection of early-life infection.

Acknowledgements. The authors are very grateful to the general practitioners who have made this study possible, to W. Atkinson for his laboratory assistance, and to the Colt Foundation for their continuing financial support.

\section{References}

1. Strachan DP, Harkins LS, Johnston ID, Anderson HR. Childhood antecedents of allergic sensitisation in young British adults. J Allergy Clin Immunol 1997; 99: 6-12.

2. Von Mutius E, Martinez FD, Fritzsch C, Nicolai T, Reitmeir $\mathrm{P}$, Thiemann H-H. Skin test reactivity and number of siblings. BMJ 1994; 308: 692-695.

3. Forastiere F, Agabitit N, Corbo GM, et al. Socioeconomic status, number of siblings and respiratory infections in early life as determinants of atopy in children. Epidemiology 1997; 8: $566-570$.

4. Shaheen SO, Aaby P, Hall AJ, et al. Measles and atopy in Guinea-Bissau. Lancet 1996; 347: 1792-1796.

5. Shirakawa T, Enomoto T, Shimazu S-I, Hopkin JM. The inverse association between tuberculin responses and atopic disorder. Science 1997; 275: 77-79.

6. Matricardi PM, Rosmini F, Riondini S, et al. Exposure to foodborne and orofecal microbes versus airborne viruses in relation to atopy and allergic asthma: an epidemiological study. BMJ 2000; 320: 412-417.

7. van den Bosch WJ, Huygen FJ, van den Hoogen $\mathrm{HJ}$, van Weel C. Morbidity in early childhood: family patterns in relation to sex, birth order and social class. Fam Med 1993; 25: $126-130$.

8. Hjern A, Haglund B and Bremburg S. Lower respiratory tract infections in an ethnic and social context. Paediatric and Perinatal Epidemiology 2000; 14: 53-60.

9. Van Spaendonck C, Reintjes R, Spanjaard L, van Kregten E, Kraaijeveld AG, Jacobs PH. Meningococcal carriage in relation to an outbreak of invasive disease due to Neisseria meningitidis serogroup C in the Netherlands. J Infect 1999; 39: $42-48$.
10. Reves R. Declining fertility in England and Wales as a major cause of the twentieth century decline in mortality. The role of changing family size and age structure in infectious disease mortality in infancy. Am J Epidemiol 1985; 122: $112-126$

11. Matricardi PM, Rosmini F, Ferrigno L, et al. Cross-sectional retrospective study of prevalence of atopy among Italian military students with antibodies against hepatitis A virus. BMJ 1997; 314: 999-1003.

12. Bodner C, Anderson WJ, Reid TS, Godden DJ. Childhood exposure to infection and risk of adult onset wheeze and atopy. Thorax 2000; 55: 383-387.

13. Matricardi PM, Rosmini F, Panetta V, Ferrigno L, Bonini S. Hay fever and asthma in relation to markers of infection in the United States. J Allergy Clin Immunol 2002; 110: 381387.

14. Björkstén B. The intrauterine and postnatal environments. J Allergy Clin Immunol 1999; 104: 1119-1127.

15. McKeever TM, Lewis SA, Smith C, et al. Early exposure to infections and antibiotics and the incidence of allergic disease: a birth cohort study with the West Midlands General Practice Research Database. J Allergy Clin Immunology 2002; 109: 43-50.

16. Bodner C, Godden D, Seaton A. Family size, childhood infections and atopic diseases. Thorax 1998; 53: 28-32.

17. Farooqi IS, Hopkin JM. Early childhood infection and atopic disorder. Thorax 1998; 53: 927-932.

18. Wickens K, Pearce N, Crane J, Beasley R. Antibiotic use in early childhood and the development of asthma. Clin Exp Allergy 1999; 29: 766-771.

19. von Mutius E, Illi S, Hirsch T, Leupold W, Keil U, Weiland SK. Frequency of infections and risk of asthma, atopy and airway hyperresponsiveness in children. Eur Respir J 1999; 14: 4-11.

20. Svanes C, Jarvis D, Chinn S, Burney P. Childhood environment and adult atopy: results from the European Community Respiratory Health Survey. $J$ Allergy Clin Immunol 1999; 103: 415-420.

21. Hesselmar B, Åberg N, Åberg B, Eriksson B, Björkstén B. Does early exposure to cat or dog protect against later allergy development? Clin Exp Allergy 1999; 29: 611-617.

22. Ownby DR, Johnson CC, Peterson EL. Exposure to dogs and cats in the first year of life and risk of allergic sensitization at 6 to 7 years of age. JAMA 2002; 288: 963972.

23. Atkinson W, Harris J, Mills P, et al. Domestic aeroallergen exposures among infants in an English town. Eur Respir $J$ 1999; 13: 583-589.

24. Tan JS. Human zoonotic infections transmitted by dogs and cats. Arch Intern Med 1997; 157: 1933-1943.

25. Gereda JE, Klinnert MD, Price MR, Leung DYM, Lie AH. Metropolitan home living conditions associated with indoor endotoxin levels. J Allergy Clin Immunol 2001; 107: 790796.

26. Hughes $\mathrm{CH}$, Baumer JH. Moving house: a risk factor for the development of childhood asthma? BMJ 1995; 311: 10691070.

27. Sunyer J, Anto JM, Harris J, et al. Maternal atopy and parity. Clin Exp Allergy 2001; 31: 1352-1355.

28. Devereux G, Barker RN, Seaton A. Antenatal determinants of neonatal immune responses to allergens. Clin Exper Allergy 2002; 32: 43-50. 